\title{
Calculation of Salinity from Neutrally Buoyant RAFOS Floats
}

\author{
Olaf Boebel, Kathy L. Schultz Tokos, and Walter Zenk \\ Institut für Meereskunde an der Universität Kiel, Kiel, Germany \\ (Manuscript received 23 February 1994, in final form 26 January 1995)
}

\section{ABSTRACT}

\begin{abstract}
A method to derive salinity data from RAFOS float temperature and pressure measurements is described. It is based on evaluating the float's in situ density from its mechanical properties and in situ pressure and temperature data. The salinity of the surrounding water may then be determined, assuming that the float has reached equilibrium with its environment. This method, in comparison with the possible use of floatborne salinity cells, has the advantage of being both cost and energy neutral and highly stable in the long term.

The effect on the estimated salinity of various parameters used in the determination of the float's in situ density is discussed. Results of seven RAFOS floats deployed in the Brazil Basin are compared with corresponding CTD data to estimate the magnitude of these errors. At present, an accuracy of 0.3 psu is achieved. The accuracy may be improved to 0.02 psu by referring the float's calculated density to a reference density established by a CTD cast at the time of launch. Results from five floats deployed in the heterogeneous water masses of the Iberian Basin are compared with the corresponding CTD casts to demonstrate the variability and interpretation of $p-T-S$ float datasets from different areas.
\end{abstract}

\section{Introduction}

RAFOS (ranging and fixing of sound) floats are increasingly used to determine the deep circulation (WCRP 1988), to trace water masses, or to tag mesoscale hydrographic features such as meddies (Mediterranean eddies) (Rossby 1988). However, the degree to which they follow the corresponding waterbody is a possible point of dispute. Both horizontal and vertical motions of the float relative to the surrounding waterbody may result in their separation. (Here, the terms "waterbody" or "corresponding waterbody" shall describe water of specific $T-S$ characteristics in the vicinity of the float at the time of launch. A "corresponding waterbody" might be visualized as the water comprising some tens of meters in the vertical and on the order of $1 \mathrm{~km}$ in the horizontal around the float.)

Classic RAFOS float designs (Rossby et al. 1986) deliver position, temperature, and pressure at typically 8-h to 2-day sampling intervals but do not feature sensors to determine salinity. Pressure and temperature alone, however, do not characterize the surrounding water unambiguously. It is possible to estimate the salinity from float data and a knowledge of the float's mechanical properties. This additional information, presented as a $T-S$ diagram, can be used to distinguish between waters of different origin and to examine the

Corresponding author address: Olaf Boebel, Abteilung Meeresphysik, Institut für Meereskunde, Düsternbrooker Weg 20, Kiel 24105, Germany.

E-mail: oboebel@ifm.uni-kiel.d400.de cause of possible relative motions between the float and the surrounding waters.

Relative motion independent of the corresponding waterbody's motion may result from shear forces or changes of the waterbody's physical properties. Downwelling or upwelling of the surrounding waters, however, introduces what we shall call a "linked relative motion," due to the different compressibilities of the float and the displaced water. An increase in pressure, for example, might indicate a descent of the float and its corresponding waterbody, provided it is reflected properly in the temperature time series (Fig. 1). It is a well-known effect (Rossby 1988) that such a pressure increase, assuming a negative $\partial T / \partial p$, has to be echoed in a temperature increase. Due to its smaller compressibility the float gains buoyancy relative to its corresponding waterbody while sinking. Thus, it does not descend as much as the downwelling waterbody and ends up in water of higher temperature (Fig. 2), even though it is deeper than before. Looking at the pressure and temperature time series or the corresponding $p-T$ diagram, however, gives a solely qualitative understanding of this process.

This shortcoming may be overcome by the use of $T-S$ diagrams. Based on Helland-Hansen's concept of the identification of water masses by $T-S$ diagrams, it is fair to say that as long as the float's $T-S$ properties adhere to the $T-S$ curve of the corresponding waterbody, the float remained within the latter and the waterbody's $T-S$ relationship was preserved. Thus, a linked relative motion within an unchanged waterbody may be identified by the coherence of the float's and 


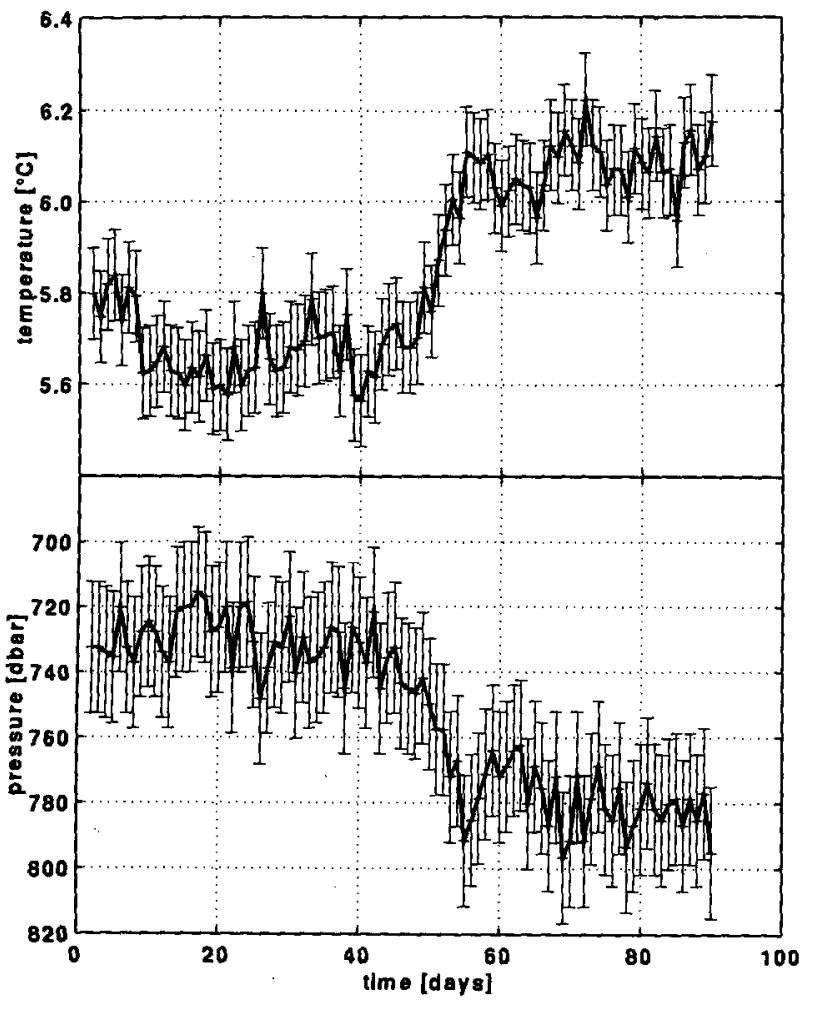

Fig. 1. Time series of float 66 temperature and pressure data. The increase in pressure around day $\mathbf{5 0}$ is clearly echoed in an increase in temperature.

the waterbody's $T-S$ properties, since the latter are independent of pressure. This does not hold true for processes resulting in an independent relative float motion.

The relatively homogeneous Antarctic Intermediate Water (AAIW) in the South Atlantic is well suited to study this kind of process and the accuracy of the proposed method of salinity estimation. After a general description of the concept of salinity calculation in section 2, float observations from the AAIW in the southwest South Atlantic are discussed in section 3. These data, in conjunction with laboratory experiments are used to evaluate the performance of the floats and the limits of this method. Section 4 is concerned with the error of the calculated salinity, based on the results of section 3 .

Floats deployed in the Iberian Basin were chosen to illustrate the use of this method in section 5 . There, at middepth (about $1000 \mathrm{~m}$ ), highly saline, warm Mediterranean Water as well as cold, less saline Subpolar Mode Water are present. Frequently, mesoscale meddies are formed, which preserve the $T-S$ characteristics of Mediterranean Water for rather long times (observations last as long as two years) (Armi et al. 1989). Floats deployed into these features are frequently expelled from the meddy, especially when deployed at its boundary. The evaluation of the $T-S$ properties of the floats is helpful to determine the time of escape.
The conclusion gives an outlook on possible improvements of this method.

It should be noted that the numerical values of errors presented depend on the specific type of float and on the ballasting procedure used. This study is based on isobaric RAFOS floats using a glass housing of 1450$\mathrm{mm}$ length, a stainless steel end plate, and a solid drop weight. However, the order of magnitude of the errors presented should hold true for similar floats, and the method can be adapted easily to other types of floats, for example, isopycnal floats (Rossby et al. 1985).

\section{Determination of salinity using RAFOS floats}

It is straightforward to calculate salinity from float data, once the underlying assumption of neutral buoyancy at in situ conditions is fulfilled:

$$
\rho_{\mathrm{fl}}\left(p_{i}, T_{i}\right)=\rho_{w}\left(p_{i}, T_{i}, S_{i}\right)
$$

The index $i$ stands for in situ conditions, fl for float, and $w$ for water. Provided $\rho_{\mathrm{f}}$ is known, one can calculate the salinity $S_{i}$, which gives the same density $\rho_{w}\left(p_{i}, T_{i}, S_{i}\right)=\rho_{\mathrm{fl}}$. This is done by simple iteration using the equation of state (Millero 1981). Since the float actually measures in situ pressure $p_{i}$ and in situ temperature $T_{i}, \rho_{\mathrm{f}}$ is calculated from

$$
\rho_{\mathrm{f}, i}=\rho_{\mathrm{fl}, T}\left[1+\alpha_{\mathrm{fl}}\left(T_{i}-T_{T}\right)+\gamma_{\mathrm{fl}}\left(p_{i}-p_{T}\right)\right] .
$$

Here $\alpha_{\mathrm{fl}}$ is the float's coefficient of thermal expansion and $\gamma_{\mathrm{fl}}$ its compressibility; $T_{T}$ and $p_{T}$ describe temperature and pressure in the pressure tank filled with deionized water $\left(S_{T}=0\right)$ in which the float had the density $\rho_{\mathrm{fl}, T}=\rho_{\mathrm{f}}\left(p_{T}, T_{T}\right)$. The pressure tank is used to determine the float's reference density to a high accuracy (Fig. 3).

To evaluate the accuracy of the derived salinity, the accuracy of the calculated float density $\rho_{\mathrm{fl}}$ (see section 3 ) and the validity of the assumption of equilibrium must be discussed. For many oceanic regions the

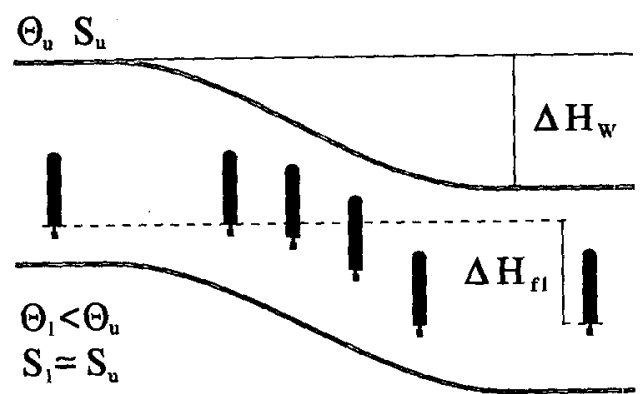

FIG. 2. Schematic of linked relative motion of float and corresponding waterbody. The float drifts within an assumed waterbody exhibiting a small salinity gradient and a negative temperature gradient $\partial T / \partial p$. If this waterbody descends, the float tries to follow. However, since it is not as compressible as the surrounding water it gains buoyancy while sinking, ending up in warmer water than before. 


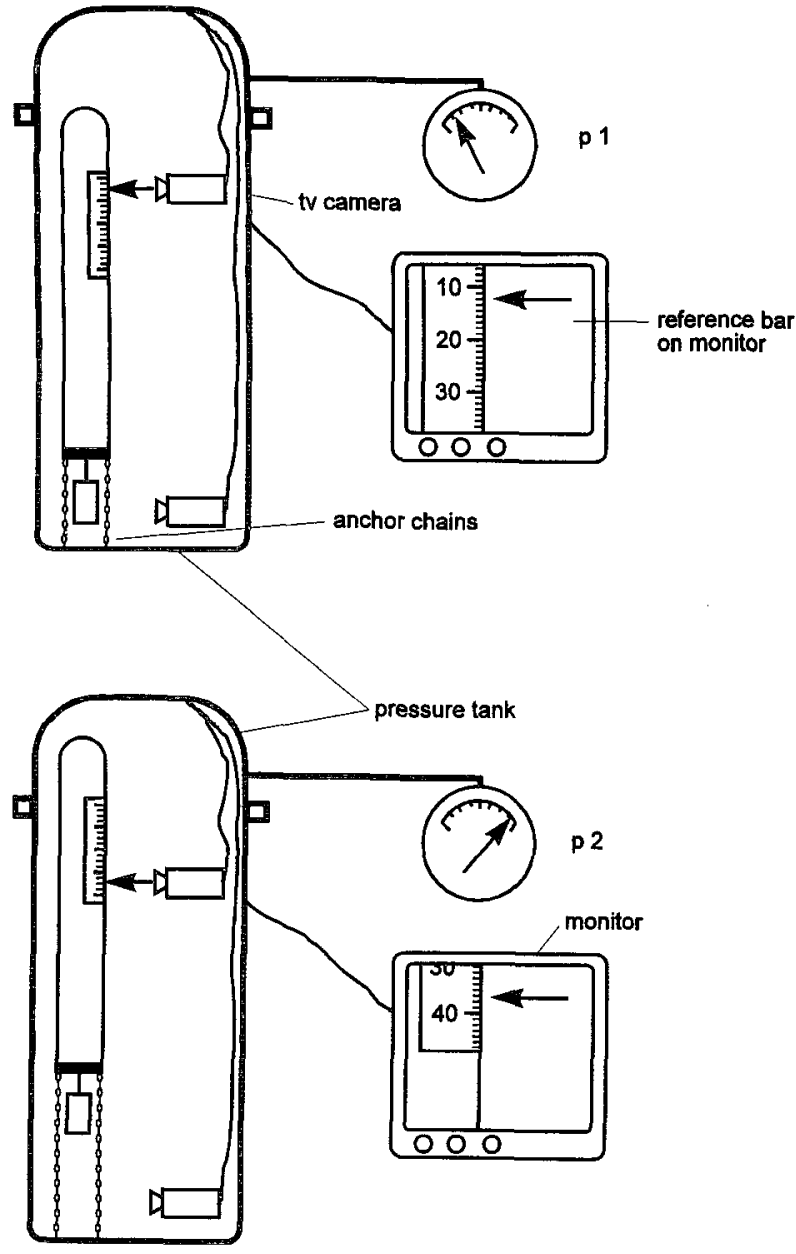

FIG. 3. A schematic of the pressure tank as used at the Institut furr Meereskunde, Kiel (König and Zenk 1992). The top depicts the situation at atmospheric pressure, the bottom at $400 \mathrm{db}$. The float is preballasted to float freely at zero pressure with two ballast chains attached. When the pressure is increased, the float gains buoyancy due to its lower compressibility and rises, thereby lifting excess chain from the tank bottom. When the combined float and chain density equals that of the tank water, the float stops and the height it rose may be read via TV cameras from a scale attached inside the float's glass housing. The height versus pressure data can be used to calculate the float's volume as a function of pressure, that is, a reference density $\rho_{\mathrm{f}, T}$ and its compressibility $\gamma_{\mathrm{f}}$.

assumption of equilibrium is reasonable. Three issues must be considered.

First, the timescale of the float's response to pressure and temperature changes is of interest. The response of the glass housing to pressure changes, apart from glass creep (see below), is instantaneous. It has been found that thermal equilibrium is reached after a few minutes. Assuming a temperature gradient of $0.01^{\circ} \mathrm{C} \mathrm{m}^{-1}$, an instantaneous displacement of $10 \mathrm{~m}$ would give rise to a maximum temperature error of $0.1^{\circ} \mathrm{C}$, which is on the order of the measurement's precision.
Second, hydrodynamic drag introduced by vertical motion of water past the float could impede the state of neutral buoyancy. Rossby (1988) calculated a driving force of 5 dyn resulting from a relative velocity of $0.3 \mathrm{~cm} \mathrm{~s}^{-1}$ for a similar type of float. Within a meddy, however, he calculates a buoyancy restoring force per meter of displacement of $25 \mathrm{dyn} \mathrm{m}^{-1}$. Thus, to obtain a depth offset of $1 \mathrm{db}$ (which is the resolution of the float's pressure measurement) a vertical velocity of 1.5 $\mathrm{cm} \mathrm{s}^{-1}\left(56 \mathrm{~m} \mathrm{~h}^{-1}\right)$ is necessary. This is very unlikely for the open ocean.

Third, a forced vertical oscillation of the float caused by a periodic displacement of the isopycnals (e.g., by internal waves) may result in a disturbance of the buoyancy equilibrium. This rather intricate scenario has been examined by Goodman and Levine (1989). Provided the float is displaced at the proper excitation
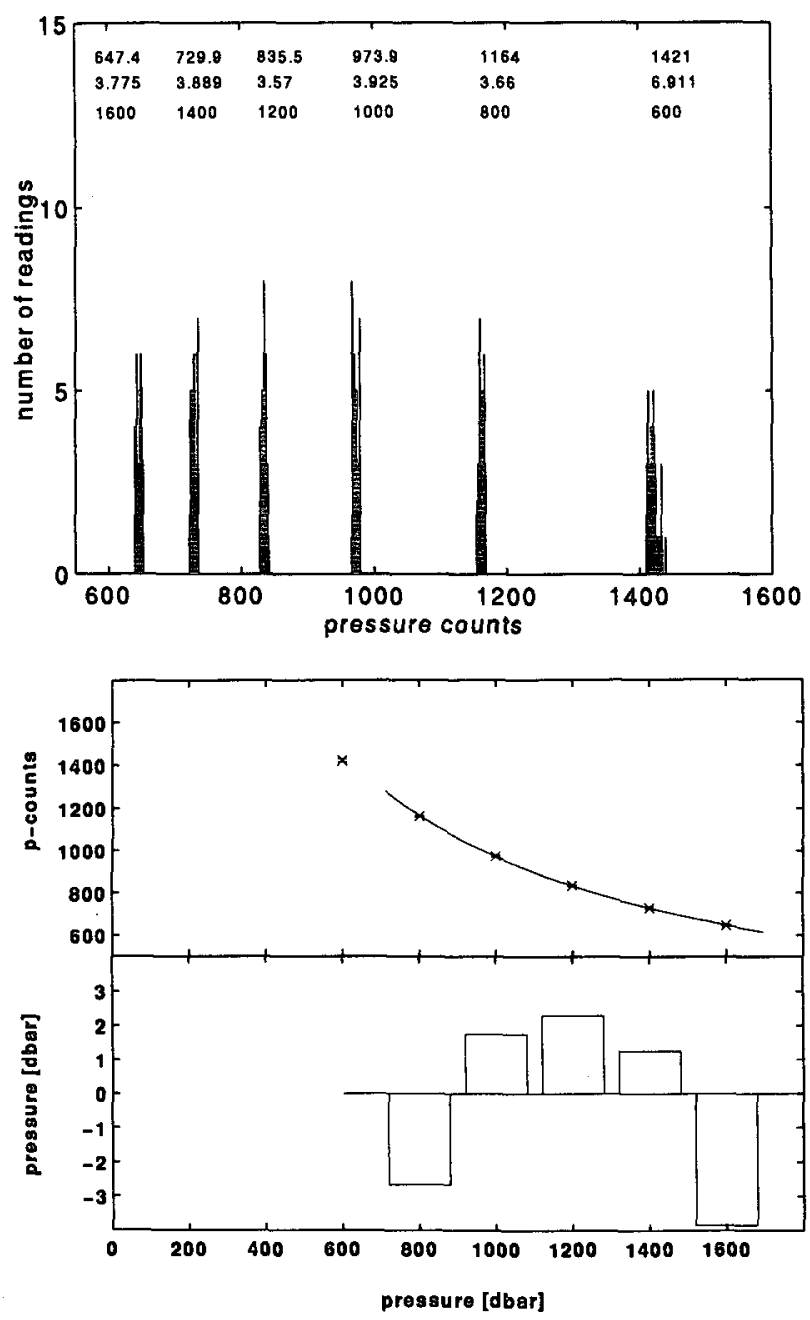

FIG. 4. (a) Number of readings versus counts of the pressure calibration of float 70 . The peaks are labeled with mean counts, standard deviation, and pressure (db) (top to bottom). (b) Fit of Eq. (3) from 800 to $1600 \mathrm{db}$ to this data (top) and the deviation of the data points from this curve (bottom). 


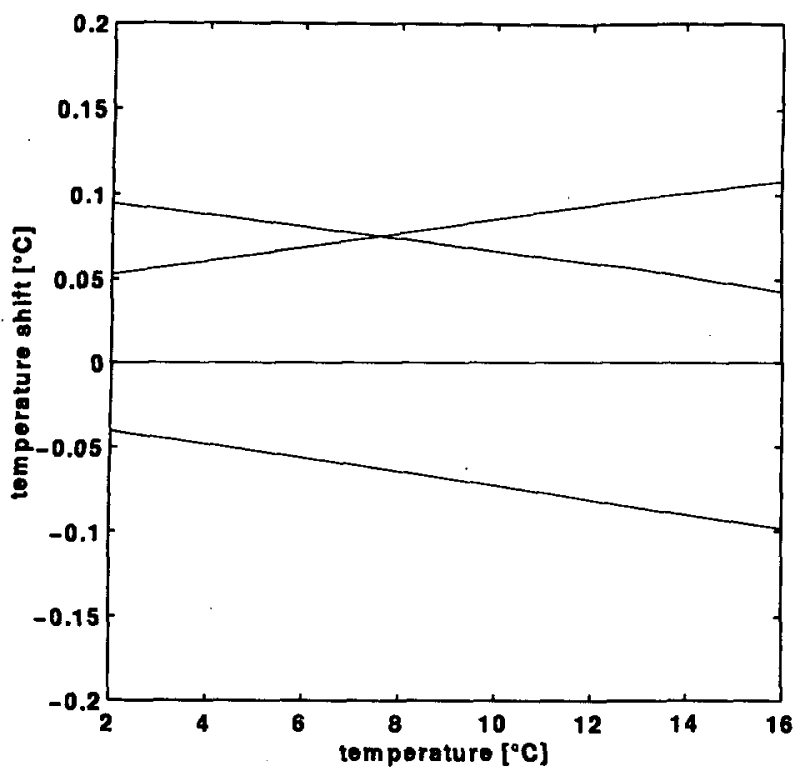

Fig. 5. Shift of calibrated temperature vs temperature when recalibrated after a period of six months for three floats.

frequency, it will eventually over- or undershoot relative to its momentary equilibrium depth. (The nature of this behavior is the well-known "resonance catastrophe," which is most drastically exhibited in the collapse of bridges). For cylindrical floats like ours, a sharp resonance occurs at the float's resonance frequency, which is slightly higher than the local buoyancy frequency. Displacements larger than the currently achieved precision of the pressure measurement (5-10 $\mathrm{db}$, see below) at the float resonance frequency ( $\omega_{0}$ $=2.7 \times 10^{-3} \mathrm{~s}^{-1}$ for this type of float in the AAIW), however, would imply vertical velocities of $1-2 \mathrm{~cm} \mathrm{~s}^{-1}$, which seems very unlikely.

\section{Sources and magnitudes of errors}

Accuracy and precision of the salinity inferred depend on three possible sources of error. The precision is determined by random errors, which have to be assigned to each data point individually. They result from statistical fluctuations of the measured data. The accuracy is, in addition, subject to systematic errors, which apply to the whole data array. They can be due to calibration errors of the pressure and temperature sensors or due to errors in the determination of the float's density, termed ballasting errors.

First, the magnitude of these errors is established from laboratory experiments and the accuracy of the gauges used in the calibration and ballasting procedures. Second, to obtain an independent check, data of seven floats launched in the Brazil Basin during $\mathrm{Me}$ teor cruise 22 in December 1992 (Siedler et al. 1993) are compared with the corresponding CTD casts.

\section{a. Accuracy of temperature and pressure measurements}

For each float, the pressure and temperature sensors, together with their electronic board, are calibrated in the laboratory. The pressure calibration is based on a deadweight tester using the weight of metal disks as reference. It is considered to be accurate to $0.05 \%$ of the measured value (VDO 1987), which amounts to $0.8 \mathrm{db}$ at the maximum calibration pressure of 1600 db. For each calibration pressure ( $600-1600 \mathrm{db}$ at 200 db steps), 50 measurements are performed (Fig. 4). The means of these calibration data (raw data in counts $C$ versus calibration pressure $p$ ) are fitted using

$$
p(\mathrm{db})=\frac{a}{C}-b
$$

to determine the coefficients $a$ and $b$ (ranging from $1.145 \times 10^{6}$ to $1.248 \times 10^{6} \mathrm{db}$ and from 98 to $331 \mathrm{db}$, respectively, for 60 floats). The variation between floats is too large to allow the use of a mean value for the calculation of salinity, as will be seen herein.

A possible difficulty in the pressure measurement is the long-term stability of the pressure sensor. This issue has been discussed during the 1994 RAFOS technology workshop at Woods Hole (Bower 1994). Both stable and unstable sensors have been found, and the origins of this behavior are still unclear. These drifts, however, have mostly been observed at pressures much higher than $1000 \mathrm{db}$. At this point, this issue must be left open, but it shall be addressed in future research.

The temperature calibration is based on the comparison of a temperature gauge and the thermistor's resistivity. The accuracy of the reference thermometer is better then $0.01^{\circ} \mathrm{C}$. Both are mounted on a copper bar, which is part of a copper container in a thermally controlled water bath. The resistivity of the thermistor is compared with a resistor decade box in a Wheatstone bridge circuit. This same resistor decade box is then used to simulate the thermistor's resistivity on the RAFOS electronic board to obtain the relationship of temperature versus counts, by measuring 100 values at each reference resistance (that is, temperature).

The calibration data $T=T(C)$ is then fitted using

$$
T(\mathrm{~K})=[a+b \ln (C)]^{-1},
$$

with $a$ ranging from $1.416 \times 10^{-3}$ to $1.526 \times 10^{-3}$ $\mathrm{K}^{-1}$ and $b$ from $2.555 \times 10^{-4}$ to $2.726 \times 10^{-4} \mathrm{~K}^{-1}$ for 60 floats. Again, the coefficients vary too rnuch for our purposes to avoid an individual calibration. The temperature calibration remained stable within $0.08^{\circ} \mathrm{C}$ during this 8-month period, as established by recalibrating three floats (Fig. 5).

To obtain an independent check of these calibration methods, we compared float data with CTD data. Figure 6 shows the uncorrected $p-T$ data of floats 66,76 , and 93 with the respective CTD cast taken approximately $2 \mathrm{~h}$ before launch. The floats showed no sign 


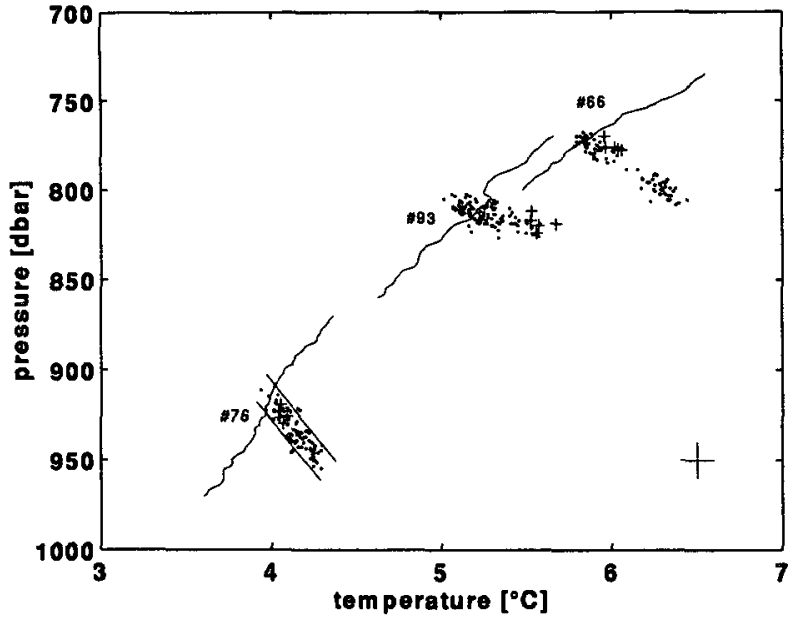

FIG. 6. Pressure vs temperature (dots) of floats 66, 76, and 93 together with their corresponding CTD casts (solid lines) at the depth range of the AAIW from the Brazil Basin. The first five data points are marked by crosses. An error cross in the lower right corner indicates the precision of the measurements. The "envelope" is depicted by two parallel solid lines for float 76 .

of sinking due to leakage or glass creep during the length of their mission for up to 6 months since the variations in pressure are reflected in variations in temperature. Three other floats $(70,88$, and 89$)$ were sinking due to a small leak (Fig. 7). This is reflected in an increase of pressure while temperature decreases correspondingly. All floats, whether sinkers or nonsinkers, show a similar offset of the first few data points compared to the CTD data $\left(\Delta p=-27 \pm 8 \mathrm{db}\right.$ or $\Delta T=-0.20^{\circ}$ $\pm 0.06^{\circ} \mathrm{C}$ ). Evaluating Figs. 6 and 7 , one must bear in mind that each CTD cast is an instantaneous mea-

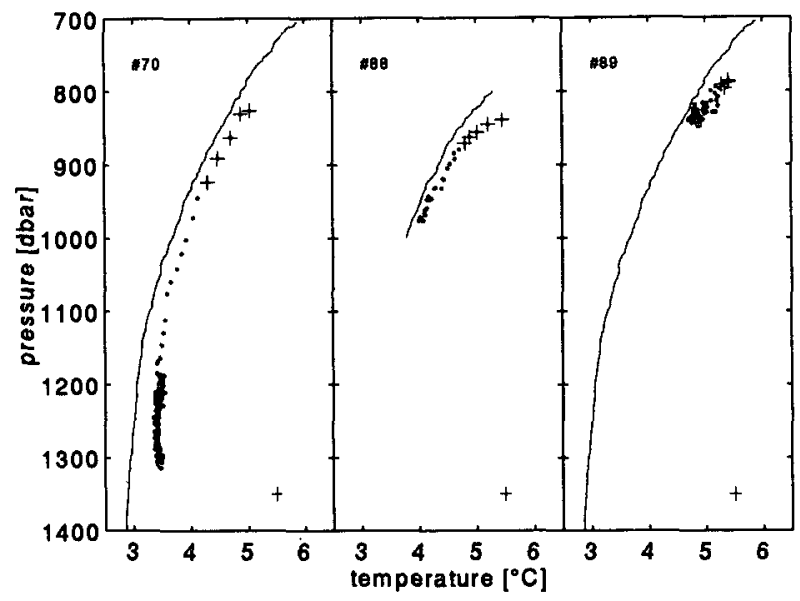

FIG. 7. Pressure vs temperature (dots) of floats 70,88 , and 89 at the depth range of the AAIW together with their corresponding CTD casts (solid lines) from the Brazil Basin. The first five data points, corresponding to the first 5 days, are marked by crosses. At the bottom right corners, error bars indicate the precision of the float data.

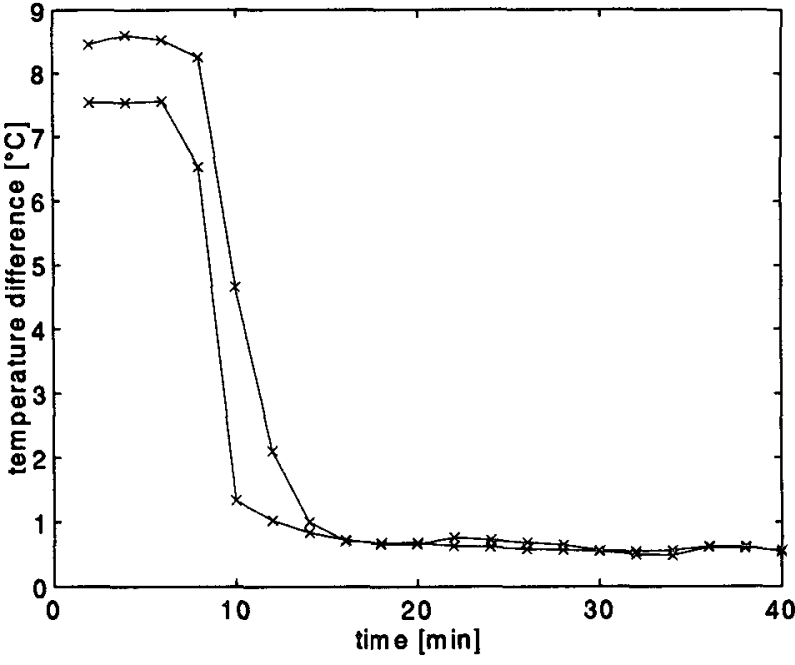

FIG. 8, Time dependence of temperature difference between tank reference thermometer and float 38 when dropped from room temperature into the pressure tank containing deionized water on two consecutive days. After approximately $10 \mathrm{~min}$ the temperature is constant to within $0.1^{\circ} \mathrm{C}$. A difference of $0.6^{\circ} \mathrm{C}\left(T_{\mathrm{f}}-T_{T}\right)$ between float equilibrium temperature and tank (thermometer) temperature $\left(16.80^{\circ}\right.$ and $15.85^{\circ} \mathrm{C}$, respectively) was observed.

surement, whereas the float data represent daily measurements up to 6 months. Thus, we are mainly interested in the correlation of the first few data points, which are marked by pluses.

This systematic discrepancy of $p-T$ data might arise from different time constants of the in situ temperature and pressure measurements. While pressure is measured instantaneously, the thermistor's response is damped, sensing the temperature of the inner wall of the glass housing. Thus, the adjustment time the float

TABLE 1. Ballasting errors. Masses $m_{c}$ of the additional stainless steel compensation weight to go from tank to in situ conditions were calculated, assuming typical errors in the parameters. This table shows the deviation in mass of the "wrong" calculation from the reference calculation. Two floats, one from the Brazil Basin project and one from the Iberian Basin project were used to simulate different in situ conditions: float $66: m_{c}=399.4 \mathrm{~g}, p_{i}=900 \mathrm{db}, T_{i}=4.61^{\circ} \mathrm{C}, S_{i}$ $=34.28 \mathrm{psu}$; float $55: m_{c}=395.3 \mathrm{~g}, p_{i}=800 \mathrm{db}, T_{i}=12.89^{\circ} \mathrm{C}, S_{i}$ $=36.35$ psu.

\begin{tabular}{llrr}
\hline \hline & & \multicolumn{2}{c}{ Float } \\
\cline { 3 - 4 } & & 66 & 55 \\
& & \multicolumn{2}{c}{ Error in calculated mass } \\
& & $(\mathrm{g})$ \\
\hline$\Delta p_{T}$ & $\pm 10 \mathrm{db}$ & $-( \pm 0.4)$ & $-( \pm 0.4)$ \\
$\Delta T_{T}$ & $\pm 1^{\circ} \mathrm{C}$ & \pm 2.5 & \pm 2.2 \\
$\Delta S_{T}$ & $+0.02 \mathrm{psu}$ & -0.2 & -0.2 \\
$\Delta m$ & $\pm 2 \times 10^{-4}$ & \pm 0.1 & \pm 0.1 \\
$\Delta \alpha_{\mathrm{fl}}$ & $\pm 50 \%$ & $-( \pm 0.9)$ & $-( \pm 0.2)$ \\
$\Delta \lambda_{\text {ket }}, \Delta h$ & $\pm 0.001 \mathrm{~g} \mathrm{~cm}^{-1}$ & \pm 0.4 & \pm 0.3 \\
$\Delta \rho_{\mathrm{V} 2 \mathrm{~A}}$ & $\pm 0.01 \mathrm{~g} \mathrm{~cm}^{-3}$ & $-( \pm 0.1)$ & $-( \pm 0.1)$ \\
\hline
\end{tabular}


TABLE 2. Errors in salinity due to calibration and ballasting errors.

\begin{tabular}{llr}
\hline \hline & \multicolumn{1}{c}{ Accuracy } & $\begin{array}{c}\text { Error in calculated } \\
\text { salinity }\end{array}$ \\
\hline $\begin{array}{l}\text { Statistical errors } \\
\delta T_{i}\end{array}$ & $\pm 0.10^{\circ} \mathrm{C}$ \\
$\delta p_{i}$ & $\pm 10 \mathrm{db}$ & $\pm 0.017 \mathrm{psu}$ \\
Calibration errors & & $-( \pm 0.014 \mathrm{psu})$ \\
$\Delta T_{i}$ & $-0.20^{\circ} \mathrm{C}$ & \\
$\Delta p_{i}$ & $-26 \mathrm{db}$ & $+0.034 \mathrm{psu}$ \\
Ballasting errors & & $-0.037 \mathrm{psu}$ \\
$\Delta p_{T}$ & $\pm 10 \mathrm{db}$ & \\
$\Delta T_{T}$ & $\pm 1^{\circ} \mathrm{C}$ & $\pm 0.033 \mathrm{psu}$ \\
$\Delta S_{T}$ & $+0.02 \mathrm{psu}$ & $-( \pm 0.238 \mathrm{psu})$ \\
$\Delta m_{\mathrm{f}}$ & $\pm 2 \times 10^{-5}$ & $+0.020 \mathrm{psu}$ \\
$\Delta \alpha_{\mathrm{f}}$ & $\pm 50 \%$ & $-( \pm 0.008 \mathrm{psu})$ \\
$\Delta \lambda_{\text {ket }}, \Delta h$ & $\pm 0.001 \mathrm{~g} \mathrm{~cm}^{-1}$ & $\pm 0.073 \mathrm{psu}$ \\
$\Delta \rho_{\mathrm{V} 2 \mathrm{~A}}$ & $\pm 0.01 \mathrm{~g} \mathrm{~cm}^{-3}$ & $-( \pm 0.032 \mathrm{psu})$ \\
& & $-( \pm 0.007 \mathrm{psu})$ \\
\hline
\end{tabular}

needs to adapt to a certain temperature change has to be considered. This time has been determined to be on the order of a few minutes (Fig. 8) so a temporal mismatch can be excluded, leaving a systematic miscalibration as the only possibility.

The ambiguity of whether the pressure or the temperature data should be corrected can be resolved by looking at the data of float 70 (Fig. 7). There, assuming a $-0.25^{\circ} \mathrm{C}$ to $-0.45^{\circ} \mathrm{C}$ offset would make the CTD and float data agree nicely over the whole pressure range, whereas a $-35-\mathrm{db}$ offset at the shallow end and over $-200 \mathrm{db}$ at the deep end are necessary to give coincidence. In addition, one float seeded into the temperature maximum level of a meddy shows a similar temperature offset toward higher temperatures. Since the float is at the depth of the temperature maximum, only a shift along the temperature axis can result in a coherence of the CTDs and the float's $p-T$ data.

Finally, an $O\left(0.25^{\circ} \mathrm{C}\right)$ offset is much more likely to occur than a 35-db pressure offset. This is due to the problem of thermal coupling between reference thermometer and thermistor during the calibration procedure. Therefore a temperature correction is the most plausible way to correct float data. Since the variation in temperature for a nonsinking float is of the order of a few tenths of degrees, a simple temperature offset should be adequate to correct for this error and will be applied in the following sections to each float individually. The procedure applied (for the South Atlantic floats) was to calculate for the first five float data points the temperature shift necessary to make float and CTD data coincide. The mean of these shifts was then applied to all the float temperature data. A thorough investigation of the causes for this miscalibration is underway.

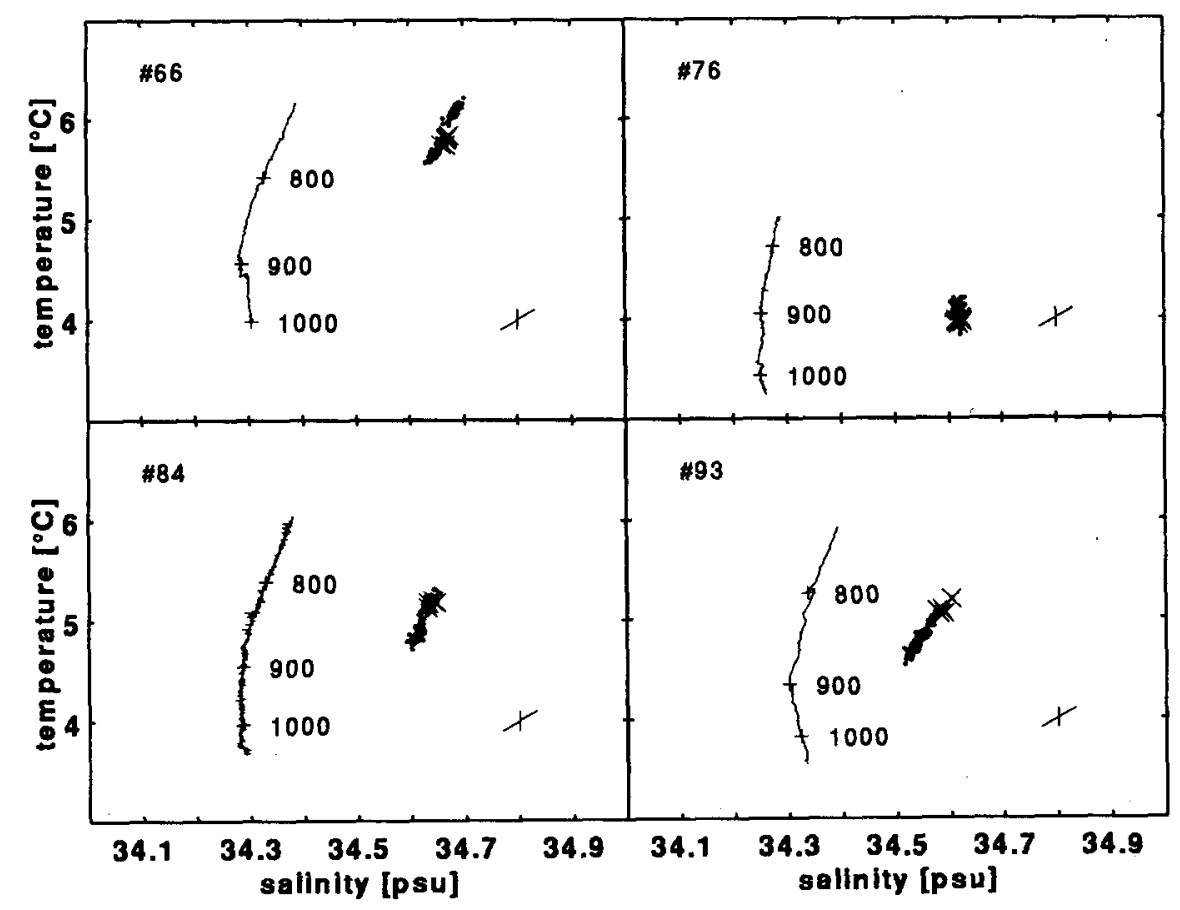

FIG. 9. Uncorrected $T-S$ diagrams for four RAFOS floats (dots and crosses for the first five days only) from the Brazil Basin. The precision of salinity and temperature is indicated by the error cross at the bottom right corner. The error bar of salinity is drawn tilted to suggest its correlation to the temperature error. The salinity minimum of the AAIW is clearly visible in the CTD casts (solid lines) at about $34.3 \mathrm{psu}$. The numbered crosses on the curve indicate the corresponding pressure $(\mathrm{db})$. 


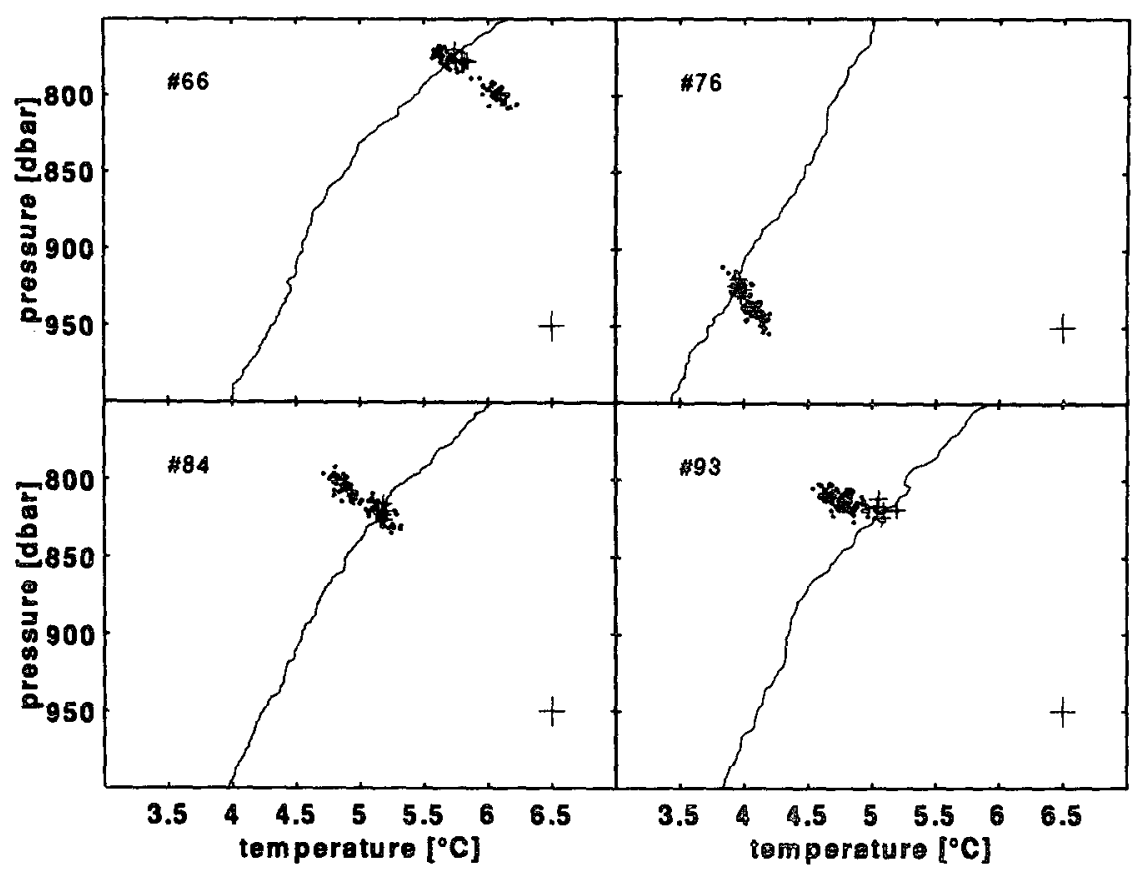

FiG. 10. The $p-T$ diagrams (dots) of floats $66,76,84$, and 93 after shift along temperature axis and the corresponding CTD casts (solid line). The following corrections were applied to the float data: float 66: $\Delta T=-0.22^{\circ} \mathrm{C}$; float $76: \Delta T=-0.10^{\circ} \mathrm{C}$; float $84: \Delta T=-0.18^{\circ} \mathrm{C}$; float $93: \Delta T$ $=-0.48^{\circ} \mathrm{C}$. The error crosses in the bottom right corners indicate the precision of the measurement. Additional crosses mark data of the first 5 days.

\section{b. Precision of temperature and pressure measurements}

As can be seen in Fig. 4, there exists a statistical distribution of "temperature" and "pressure counts" at a given reference temperature or pressure. The width of this distribution is less then $\delta T= \pm 0.08^{\circ} \mathrm{C}$ for temperature, and less than $\delta p= \pm 10 \mathrm{db}$ for pressure measurements (maximum variation of all floats calibrated to date). This distribution is bimodal rather than Gaussian and is believed to stem from a slight incompatibility between the software and hardware used. Other float designs show a better performance. In comparison, the "envelope" as indicated by two parallel solid lines in Fig. 6 of the data of several nonleaking floats indicate a relative error of $\delta p= \pm 10 \mathrm{db}$ and $\delta T$ $= \pm 0.14^{\circ} \mathrm{C}$, which is of the same order as the statistical error observed in the laboratory. A precision of $10 \mathrm{db}$ and $0.1^{\circ} \mathrm{C}$ will be assumed.

\section{c. Error in determining float density}

To calculate the float's in situ density $\rho_{\mathrm{f}, i}$ [Eq. (2)], a reference density $\rho_{\mathfrak{n}, T}$ at a reference pressure $p_{T}$ and temperature $T_{T}$, the float's compressibility $\gamma_{\mathrm{f}}$ and its coefficient of thermal expansion $\alpha_{\boldsymbol{n}}$ must be known. All parameters, except $\alpha_{\mathrm{fl}}$, are determined independently for each float. The general concept of float ballasting is described in Rossby et al. (1985) and recently by Swift and Riser (1994). The modifications to the facilities in Kiel may be found in König and Zenk (1992) and shall not be repeated here. The errors of the parameters involved in the calculation of float density will be discussed in the sections below to obtain an estimate of the float density error (e.g., the uncertainty in the "compensation weight" $m_{c}$ added to go from tank to in situ conditions). The reference density $\rho_{\mathrm{ff}, T}=\rho_{\mathrm{fl}}\left(m_{\mathrm{fl}}, p_{T}, T_{T}, S_{T}, m_{\mathrm{ch}}\right)$ depends on parameters measured during the tank ballasting procedure.

The float mass $m_{\mathrm{f}}$ can be determined accurately. A recalibration of our scale after about 2 years of use gave a $+2-\mathrm{g}$ offset at $10 \mathrm{~kg}$. This amounts to a relative error of $2 \times 10^{-4}$, which will be used for all mass determinations.

The tank pressure $p_{T}$ is determined by a pressure gauge identical to those used in the floats. Several calibrations and comparisons of float pressure and tank pressure measurements show a maximum error of 10 $\mathrm{db}$ at a nominal pressure of $400 \mathrm{db}$. The results of the float-CTD comparison described above show that the pressure calibrations are accurate.

The tank temperature has proven to be the most difficult measurement. We observed a gradient of $1.5^{\circ} \mathrm{C}$ top to bottom after the tank stood idle for a few days. Furthermore, we observed a deviation of $0.8^{\circ} \mathrm{C}$ between a test float and the indicated tank temperature (Fig. 8). Thus, an error of $1^{\circ} \mathrm{C}$ is possible. 


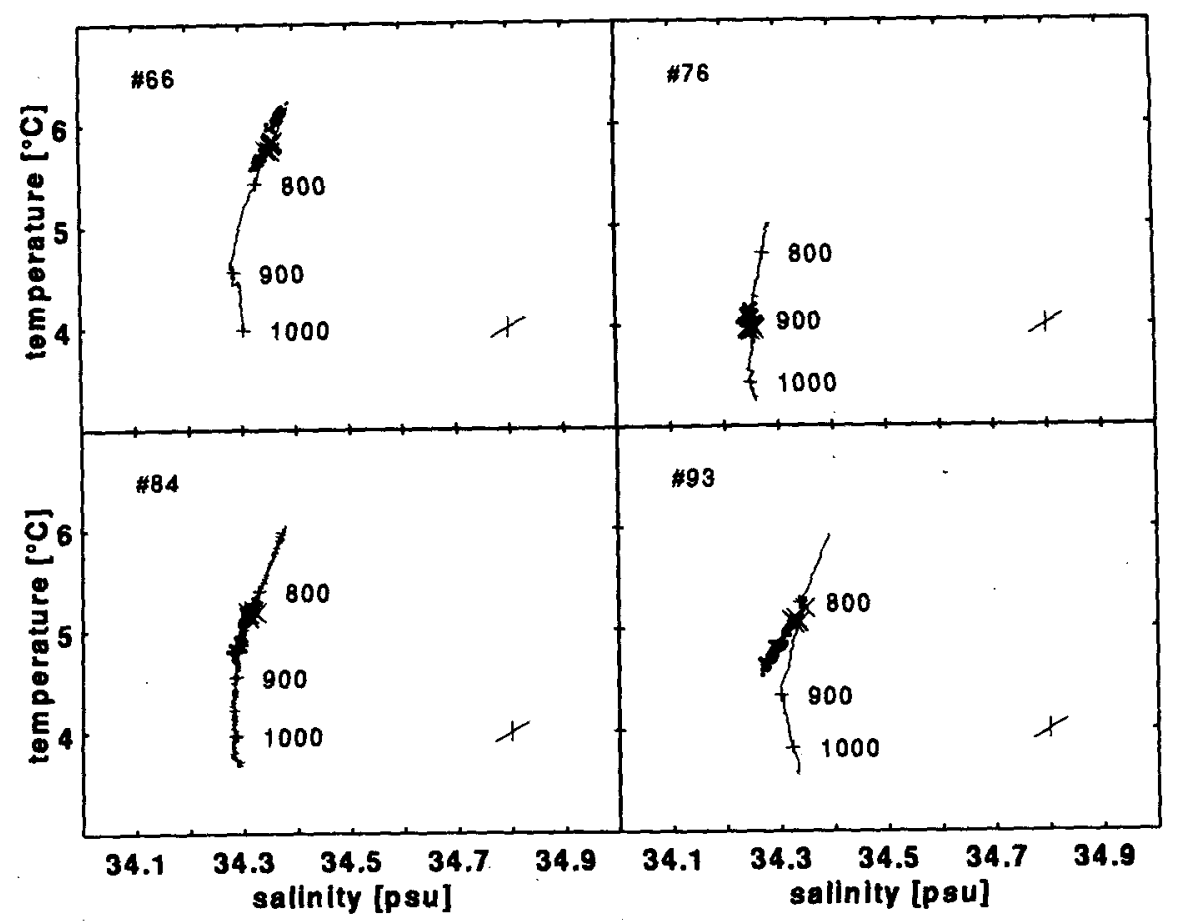

FIG. 11. The $T-S$ diagrams (dots and crosses for the first 5 days only) calculated as described in the text, including the correction of the tank temperature as follows: float $66: \Delta T_{T}=1.13^{\circ} \mathrm{C}$; float 76: $\Delta T_{T}=1.39^{\circ} \mathrm{C}$; float $84: \Delta T_{T}=1.22^{\circ} \mathrm{C}$; float $93: \Delta T_{T}=0.70^{\circ} \mathrm{C}$. The solid curve represents the corresponding CTD cast; unlabeled numbers indicate pressure (db). Error bars in the lower right corner represent the precision of the data.

The term "tank salinity" is extended to include the effect of minerals in the water on density. We used deionized water to minimize this effect. The equivalent tank salinity has been determined to be less than 0.02 psu.

The (wet) mass of the anchor chains lifted $m_{\mathrm{ch}}$ (Fig. 3 ) depends on the accuracy of measuring the float's position relative to the tank bottom as well as the ac- curacy of the chain's linear density. The linear density $\lambda_{\text {ket }}$ has been determined several times to be 0.1856 $\pm 0.0009 \mathrm{~g} \mathrm{~cm}^{-1}$. The float's height $h$ over the tank bottom at $400 \mathrm{db}$ is determined by linear regression within $\Delta h= \pm 0.5 \mathrm{~cm}$, which amounts in total to an error of less than $\pm 0.2 \mathrm{~g}$.

To go from tank to in situ conditions, Eq. (2) is applied with $\rho_{\mathrm{f}, i}=\rho_{\mathrm{fl}}\left(\rho_{\mathrm{f}, T}, \alpha_{\mathfrak{f}}, T_{T}, T_{i}, \gamma_{\mathrm{f}}, p_{T}, p_{i}, \rho_{\mathrm{V} 2 \mathrm{~A}}\right)$.

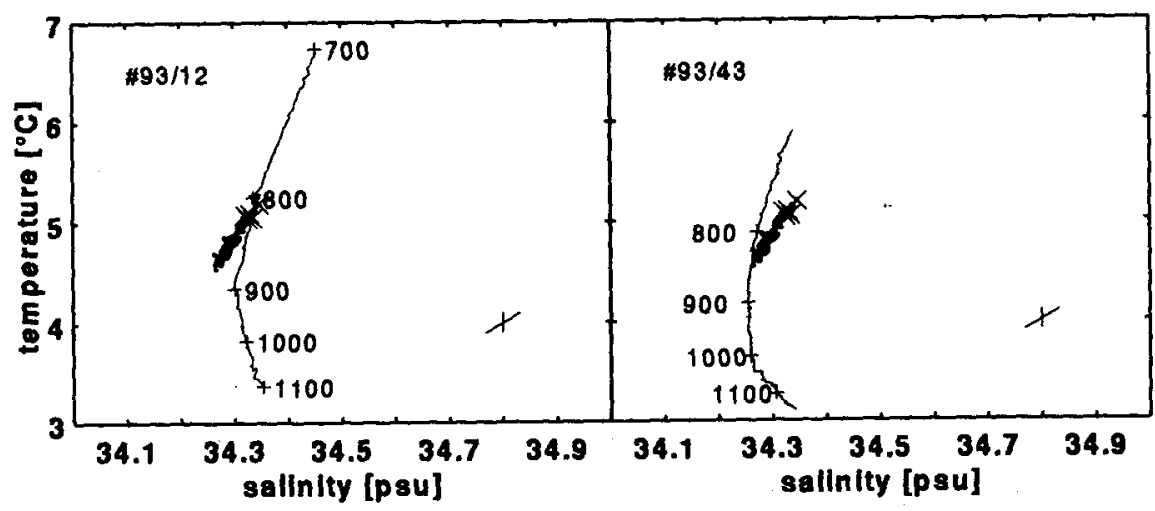

Fig. 12. The $T-S$ diagrams of float 93 compared to CTD casts 12 and 43 . CTD 12 was taken when the float was launched; 43 is a CTD farther west, taken at the beginning of the trajectory of float 70 crossing that of float 93 twice. The numbers at the curve indicate the corresponding pressure (db). 


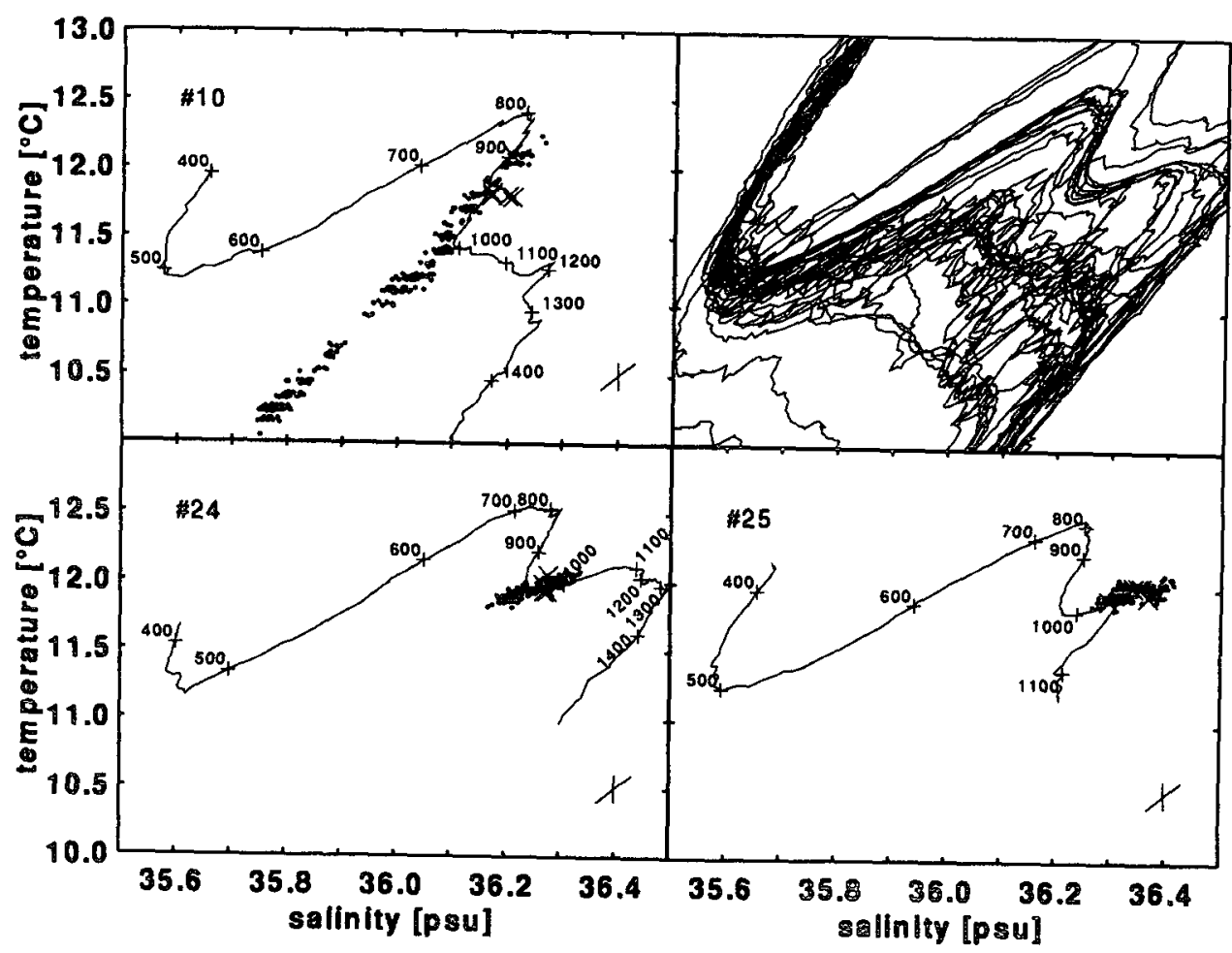

FIG. 13. The $T-S$ diagrams (dots and crosses for the first four data points only) of floats 10,24 and 25 corrected for tank temperature in comparison with the corresponding $T-S$ diagram of a CTD cast (solid line) when the respective float was launched and a summary $T-S$ diagram (top right) of CTD stations taken around meddy ASKA (Schultz Tokos et al. 1994). Unlabeled numbers at the solid curve indicate the corresponding pressure (db). Corrections applied: float 10: $\Delta T=-0.60^{\circ} \mathrm{C}, \Delta T_{T}=0.31^{\circ} \mathrm{C}$; float $24: \Delta T$ $=-0.67^{\circ} \mathrm{C}, \Delta T_{T}=0.32^{\circ} \mathrm{C}$; float $25: \Delta T=-0.61^{\circ} \mathrm{C}, \Delta T_{T}=-0.54^{\circ} \mathrm{C}$. The temperature calibration was performed differently from the method described above, explaining the high deviation in the float temperature.

Besides the CTD data $\left(p_{i}, T_{i}\right)$, which is assumed here to be free of error, the accuracies of $\alpha_{\mathrm{fl}}, \gamma_{\mathrm{fl}}$, and of the density of the additional stainless steel weight $\rho_{\mathrm{V} 2 \mathrm{~A}}$ have to be considered.

The float compressibility $\gamma_{\mathrm{f}}$ is determined from float volume measurements at two different reference pressures. The compressibility ranges from $-3.448 \times 10^{-6}$ to $-3.137 \times 10^{-6} \mathrm{~b}^{-1}$ for 60 floats. However, the compressibility $\gamma_{\mathrm{f}}$ is an intermediate property derived from the more fundamental properties mentioned above. Thus, the influence of the compressibility error on the compensation weight is included in the discussion of the other parameters.

The volume coefficient of thermal expansion is calculated from the floats' geometry as three times the linear coefficient of thermal expansion of borosilicate glass, or $1 \times 10^{-5} \mathrm{~cm}^{3}{ }^{\circ} \mathrm{C}^{-1}$. The error of $\alpha_{\mathrm{f}}$ is not known, but a $\pm 50 \%$ deviation was assumed to be very conservative.

The density of the stainless steel compensation weight added to go from tank conditions to in situ conditions has been measured several times. The density of this steel is $\rho_{\mathrm{V} 2 \mathrm{~A}}=7.908 \pm 0.009 \mathrm{~g} \mathrm{~cm}^{-3}$.
Table 1 compiles the effects of these parameters on the calculation of the additional weight necessary to make the float neutrally buoyant at in situ conditions. For each parameter, errors as described above are assumed. Again, the dominant error is the tank temperature. This parameter affects both the calculation of the float's reference density as well as the factor $\left(T_{i}\right.$ $-T_{T}$ ) in the thermal expansion term of Eq. (2). To calculate the deviation in depth corresponding to a certain excess mass, the stratification of the surrounding water has to be considered. For this type of float and our present target areas (AAIW or meddies), $1 \mathrm{~g}$ heavy (light) corresponds to approximately $40 \mathrm{~m}$ deep ( shallow). Thus, the tank temperature is the only quantity that could explain the observed deviation between target and actual depth of the South Atlantic floats. These became neutrally buoyant $60-130 \mathrm{db}$ above the target depth.

\section{d. Glass creep}

A few remarks are necessary when addressing the issue of glass creep, which might impede the long-term stability of this method. Using a dummy float to mon- 


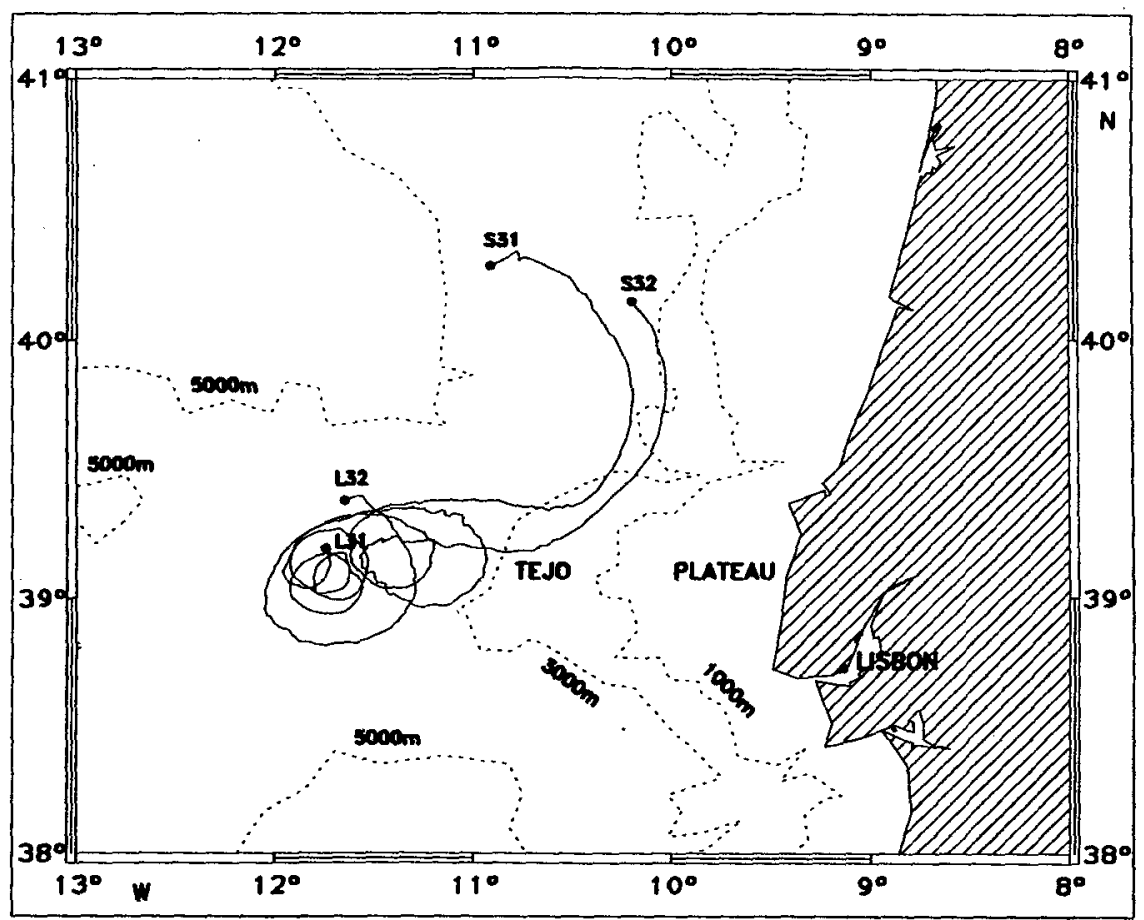

Fig. 14. Trajectories of floats 31 and 32 in the Iberian Basin. These floats were launched from RV Suroit on 14 May 1992 (L-launch, S-surface positions). Their mission length was three months.

itor the tank water quality, the same glass tube was taken five times to $400 \mathrm{db}$ for approximately $30 \mathrm{~min}$. The measurements took place from January 1993 to May 1994 under varying tank temperature conditions. Glass creep would result in decrease of float volume with time. A decrease in volume, on the other hand, would result in a smaller compensation weight nec-

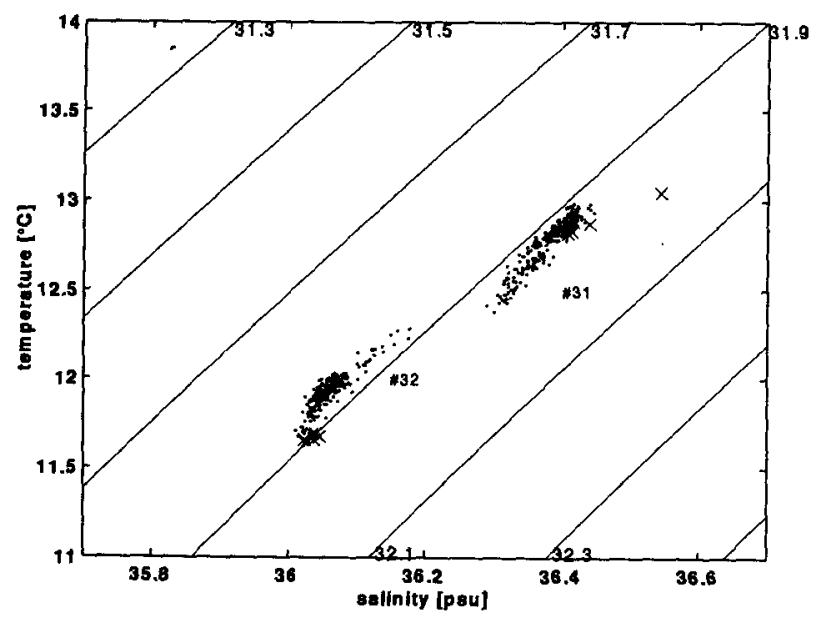

FIG. 15. The $T-S$ diagram of floats 31 and 32 (dots and crosses the first four data points only). The solid lines represent isopycnals $\left(10^{-3} \mathrm{~g} \mathrm{~cm}^{-3}\right)$ referenced to $1000 \mathrm{db}$. essary to make the float neutrally buoyant at the same depth under (assumed) in situ conditions. The compensation weight was calculated for each ballasting, resulting in $401.7,399.9,399.8,400.4$, and $400.7 \mathrm{~g}$ in chronological order. Thus, after a first decrease of the float volume, it slightly increased from ballasting to ballasting, which does not comply with glass creep at $400 \mathrm{db}$.

Riser (1994, personal communication ) reported recently of 25 floats at $3000 \mathrm{~m}$ ( 16 floats) and $1000 \mathrm{~m}$ ( 9 floats) for 2 years, similar to our design. Most of the 1000-db floats did not show any trend in the pressure data. However, a few, mostly deep floats did exhibit a slow pressure increase $(50 \mathrm{db})$ over 2 years.

These results are, due to the errors involved, not a clear-cut proof that glass creep does or does not occur at $1000 \mathrm{db}$. However, they state that a possible glass creep is not higher than the intrinsic errors of the sensors used so far. It is worth noting that a possible descent of the float due to glass creep might be masked by the occasionally observed drift of the pressure sensor. To settle this issue, an experiment with floats featuring very precise sensors or a long-term tank experiment is needed.

\section{Accuracy and precision of inferred salinity}

A number of calculations were performed to estimate the influence of a miscalibrated or misballasted float 
on calculated salinity. The results are listed in Table 2. To simulate a miscalibration of pressure or temperature, the assumed error was simply subtracted from the data, and the salinity was recalculated. To simulate errors in the ballasting procedure, the particular parameter was modified in the ballasting programs. Then, density and compressibility were recalculated. These were used to calculate a modified salinity. Thus, the modification's influence on both the calculated reference volume and compressibility is taken into account.

The precision of the derived salinity may be calculated from the precision of the temperature and pressure measurements involved, since these are the only parameters showing statistical fluctuations. The temperature measurement is considered to be reproducible within $\pm 0.1^{\circ} \mathrm{C}$, the pressure measurement within \pm 10 $\mathrm{db}$. Assuming independence of these errors, the precision of salinity may be calculated (compare Table 2):

$$
\epsilon_{s}(\mathrm{rel})=\left(0.017^{2}+0.014^{2}\right)^{1 / 2} \mathrm{psu}=0.022 \mathrm{psu} \text {. }
$$

This error is indicated in the $T-S$ diagrams (Fig. 9) by an error bar in the bottom right corner. Since there is a correlation between temperature and the calculated salinity values, the error bar of salinity is drawn tilted in the $T-S$ diagram, indicating its relation to the corresponding temperature value.

Using all but the statistical errors listed in Table 2 and assuming their independence, the accuracy of the inferred salinity under the conditions described can be calculated as

$$
\epsilon_{s}(\mathrm{abs})=0.288 \mathrm{psu} \text {. }
$$

This agrees well with the deviation observed in Fig. 9, comparing salinity calculated from uncorrected float data with the corresponding CTD cast. Again, the uncertainty in the tank temperature is responsible for most of the absolute error. If this error were eliminated, the accuracy would reach $0.088 \mathrm{psu}$. In addition, since the assumed error in $\alpha_{\mathrm{f}}$ is probably much too high, the accuracy would even reach $0.049 \mathrm{psu}$ if $\Delta \alpha_{\mathrm{fl}}=0.1 \alpha_{\mathrm{fl}}$ were chosen.

To account for the systematic errors observed, the float data were normalized. First, a constant temperature offset was applied to the data to make the first 5day $p-T$ average coincide with the corresponding CTD data (Fig. 10), which is equivalent to a shift along the $T$ axis in the $p-T$ diagram. Second, the corresponding CTDs data were used to calculate the density of the water at the float's first 5-day mean pressure level. Then, the tank temperature, being the most probable error in the ballasting procedure, was adjusted until the float's recalculated density (mean of the first 5 days) would equal the density based on the CTD data. This can be pictured as a shift of the float data to the CTD data along the salinity axis (Fig. 11) in a $T-S$ diagram. This normalization inverts the idea underlying this paper, since float density is now based on the correspond- ing CTD data, but only for the first five data points. Resuming the salinity calculation using the revised tank temperature, the remaining $T-S$ data still holds very interesting information, as will be seen herein.

The $p-T$ diagrams (Fig. 10) of the South Atlantic floats show a deviation of the float data from the CTD data, which might reflect linked relative motion of floats and corresponding waterbody as described in the introduction. The strong correlation of the CTD casts' $T-S$ diagrams and the floats' $T-S$ diagrams in Fig. 11 indicates that floats 66,76 , and 84 stayed within their corresponding waterbody, whereas float 93 experienced some modifications.

The trajectory of float 93 crosses the trajectory of float 70 twice. Comparing the data of float 93 to the CTD taken when float 70 was launched, gives good agreement in $T-S$ space (Fig. 12) for the last data points. This hints to a water exchange between these two waterbodies.

\section{Application to the Mediterranean Water tongue}

Data of five floats launched in the Iberian Basin have been evaluated accordingly. To demonstrate the high variability in salinity, which might be observed by a float in this area, we chose three floats launched into meddy ASKA at $38.5^{\circ} \mathrm{N}, 13.5^{\circ} \mathrm{W}$ on 26 May 1991 , from FS Poseidon, cruise $182 / 4$. The float data have been compared to a simultaneous quasi-synoptic CTD survey (Schultz Tokos et al. 1994). Floats 24 and 25 stayed within this meddy for the complete 1 -month mission, whereas float 10 left this structure after approximately 75 days. The absolute $T-S$ values (that is no tank temperature correction applied) are close to the corresponding CTD values. (This coincides with repeated thorough stirring of the tank's water before ballasting.) Shifting the float data in $T-S$ space as described above, leads to an excellent agreement of the float and CTD data (Fig. 13), keeping the high variability in this area in mind. The $T-S$ diagrams of floats 24 and 25 are rather compact, whereas float 10 covers a wide range in $T-S$ space, reflecting the float's movement through different water masses (Hinrichsen et al. 1993).

Different from the renormalization procedure used for the South Atlantic floats, these floats were adjusted to their first valid data point solely. This seems adequate because of the strong inhomogeneities within the Mediterranean Water tongue. In general, it is somewhat subjective, which points to use to shift the data to. Float 25 might as well be shifted according to the second point, since the first data point was acquired only four hours after launch, thus the float might not have been at equilibrium at the time. This shift would lead to a better agreement, but the CTD cast itself is peculiar, exhibiting a diminished lower local salinity maximum. For consistency, the first data point was chosen as a reference. 
Nonetheless, one can clearly distinguish between floats 24 and 25 keeping close contact with the waterbody that they were launched in, and 10 , passing a whole range of $T-S$ profiles, by looking at the array of $T-S$ profiles presented in Fig. 13 (upper right corner).

Among many, two floats ( 31 and 32) from If M Kiel were launched during the French experiment SAMBA0 on 14 May 1992 (Ollitrault 1993), which are presented to further illustrate the use of calculating salinity from RAFOS float data. Their missions lasted for three months. Both trajectories (Fig. 14) exhibit first an anticyclonic movement, which is transformed later on to a larger-scale cyclonic movement. Interpreting these data, one is interested in determining whether this transition is due to the floats being expelled from the original waterbody or due to a changing flow pattern.

Surprisingly, looking at the $T-S$ diagrams (Fig. 15), it is easily recognized that the properties of the water masses surrounding floats 31 and 32 change little in salinity and temperature. It is plausible to conclude, even with no CTD data from the launch position, that floats 31 and 32 stayed with their initial waterbody, which is slightly modified later on while moving northwest and northeast. It is noteworthy that the initial salinity calculated for float 31 equals $36.6 \mathrm{psu}$. This was exactly the maximum core salinity observed a week earlier by the French team at almost the same site (M. Ollitrault 1992, personal communication ).

\section{Conclusions}

It was demonstrated that salinity can currently be inferred from uncorrected RAFOS float data to better than 0.3-psu accuracy and 0.02-psu precision. These calculations require an independent calibration and careful ballasting for each float. The accuracy can be improved to reach the magnitude of the precision by normalizing the float data with respect to a CTD cast taken at the time of deploying the float. Even further, by thoroughly controlling the tank temperature, an accuracy of less than 0.05 psu should be achievable without applying any corrections. The long-term accuracy is somewhat impeded by a possible offset of the pressure gauge, which is not too large $(0.014$ psu per $10 \mathrm{db})$ or by glass creep. The current precision is subject to the software and hardware used and might be improved by using new designs.

The resulting $T-S$ diagrams are well suited to distinguish between different water masses, to pinpoint horizontal mixing processes, or to observe vertical displacements of the waterbody with which the float is drifting.

Further investigations are planned to understand possible sensor drifts and to improve precision and stability of the pressure and temperature measurements. Meanwhile, the pressure tank was equipped with an additional deadweight tester to verify the readings of the reference pressure gauge and with three thermistors to check its vertical temperature gradient. A pump will now be used to ensure thorough stirring before each ballasting cycle.

Acknowledgments. With pleasure we acknowledge the technical assistance of U. Huenninghaus, P. Meyer, and M. Möllenhoff who all were deeply involved in the laboratory and field experiments. We enjoyed the support of Dr. M. Ollitrault during the SAMBA0 cruise on RV Suroit and subsequent recoveries of floats. The officers and crews of FS Alkor, FS Meteor, and FS Poseidon substantially contributed to the success of this project. Discussions with Dr. Thomas Rossby were very helpful and motivating, especially in the early stage of this work, while he was on sabbatical at the Institut für Meereskunde. We appreciate the support of Deutsche Forschungsgemeinschaft (SFB133 and Ze 145/6-1).

\section{REFERENCES}

Armi, L., D. Hebert, N. Oakey, J. F. Price, P. L. Richardson, H. T. Rossby, and B. Ruddick, 1989: Two years in the life of a Mediterranean salt lens. J. Phys. Oceanogr., 19, 354-370.

Bower, A. S., 1994: Pressure transducer tests-1986. RAFOS Float Technology Workshop Proc., Woods Hole, MA, Woods Hole Oceanogr. Inst., 98-107.

Goodman, L., and E. R. Levine, 1989: Vertical motion of neutrally buoyant floats. J. Atmos. Oceanic Technol., 7, 38-49.

Hinrichsen, H.-H., M. Rhein, R. H. Käse, and W. Zenk, 1993: The Mediterranean Water Tongue and its chlorofluoromethanes signal in the Iberian Basin in early summer 1989. J. Geophys. Res., 98(C5), 8045-8412.

König, H., and W. Zenk, 1992: Principles of RAFOS technology at the Institut für Meereskunde Kiel. Ber. Inst. Meereskd., 222, $99 \mathrm{pp}$.

Millero, F., and A. Poisson, 1981: International one atmosphere equation of state of seawater. Deep-Sea Res. A, 28, 625-629.

Ollitrault, M., 1993: The SAMBA0 experiment: A comparison of subsurface floats using the RAFOS technique. WOCE Newsletter, 14, 28-32.

Richardson, P. L., M. S. McCartney, and C. Maillard, 1991: A search for meddies in historical data. Dyn. Atmos. Oceans, 15, 241265.

Rossby, T., 1988: Five drifters in a Mediterranean salt lens. DeepSea Res., 35, 1653-1663.

- E. R. Levine, and D. N. Connors, 1985: The isopycnal Swallow Float-A simple device for tracking waterbodies in the ocean. Progress in Oceanography, Vol. 14, Pergamon, 511-525.

- D. Dorson, and J. Fontaine, 1986: The RAFOS System. $J$. Atmos. Oceanic Technol., 3, 672-679.

Schultz Tokos, K., H.-H. Hinrichsen, and W. Zenk, 1994: Merging and migration of two meddies. J. Phys. Oceanogr., 24, 21292141.

Siedler, G., W. Balzer, T. J. Müller, R. Onken, M. Rhein, and W. Zenk, 1993: WOCE South Atlantic 1992 Cruise Rep. No. 22, 22 September 1992-31 January 1993. Meteor Berichte Univ. Hamburg, Vol. 93-5, 131 pp.

Swift, D. D., and S. C. Riser, 1994: RAFOS floats: Defining and targeting surfaces of neutral buoyancy. J. Atmos. Oceanic Technol., 11, 1079-1092.

VDO Mess- und Regeltechnik GmbH, 1987: Betriebsanleitung Hydraulische Prüfeinrichtung für Druckmeßgeräte, $6 \mathrm{pp}$.

WCRP, 1988: WOCE Implementation plan. Vol. 1. World Climate Research Programme 11, WMOITD No. 242, 74 pp. 